كلمة التحرير

\title{
شيخنا محمد الغزالي رحمه الله \\ وصفحات من حياته
}

رئيس التحرير

حين يذكر الشيخ ججمد الغزالي تتبادر إلى الأذهان جملة خصال قلَّ أن تتوافر كلها أو بتحتمع بجملتها في عَالمِ معاصر، ومن هذه الخصال الحمديدة:

1- الاجتهاد القائم على سعة الإسلام ومرونته ومقاصد شريعته وكليات مصادره، وغاياته العليا.

2- السماحة والاعتدال اللّذان ينبّهان بوضوح إلى الفهم الدقيق للوسطية الإسلام"، والإدراك العميق لقيمه العليا (التوحيد والعمران والتزكية)، والفقه المستفيض في معيار الإسلام الأساس (العدل) الذي منه انبثق "الاعتدال"، واشتقّت "الوسطية".

3- الغيرة الصادقة على "الأمة القطب" التي انتمى إليها بعقله وقلبه ووجدانه فضلاً عن دمه وجسده، غيرةً على دينها وأرضها وعرضها وأبنائها وماضيها وتاريخها ومستقبلها ووحدةقا.

4- القدرة النقدية، والطاقة العقلية، والمعرفة المتنوعة الواسعة، والذكاء الخنارق اللمّاح، والطاقة المتجددة المتطلعة -على الدوام- إلى معرفة الجديد والمزيد ف يكل ما من شأنه أن يخدم هذه الأمة وقضاياها المتشعبة. 5- الحب والوفاء لربه ولنبه ودينه وأمته ورفاقه وتلامذته، يساعده على ذلك قلب كبير نقي من الغل والحقد والحسد والبغضاء والكراهية، خالص للإيمان والحب والوفاء.

ذلك إلى خصال أخرى كثيرة تحدَّث عنها المتحدثون من محبيه وتلامذته وعارفي فضله قبل أن يرحل

$$
\text { عن دنيانا وبعد ذلك. }
$$

ولا أود أن أعيد شيئاً مما قالوه، ولكنني أود أن أفتح صفحات معدودة من حياته الحافلة، لأنّ فيها من

$$
\text { الدروس والعبر ما هو جدير بالإذاعة والإشاعة. }
$$


وسأبدأ بالعلاقة الوثيقة التي ربطت بين الشيخ الغزالي و"المعهد العالي للفكر الإسلام"، وما كان لها

$$
\text { من أثر في بعض توجيهاته الفكرية. }
$$

بدأت صلة الشيخ الغزالي بالمعهد العالمي للفكر الإسلامي بعلاقات الصداقة الوثيقة والحميمة التي

$$
\text { ربطت بينه وبين رجال المعهد ومؤسسيه قبل أن يؤسس رسمياً في الولايات المتحدة الأمريكية. }
$$

فالشهيد الدكتور إسماعيل الفاروقي قد اتصلت أواصر الصداقة بينه وبين الشيخ -رممه الله- منذ أن

ترجم إلى اللغة الإنجليزية كتابه، من هنا نعلم الذي ردّّ الشيخ فيه على كتاب من هنا نبدأ للشيخ خالد محمد خالد -رممهم الله جميعا-. يقول الشهيد الفاروقي: "كنت قد اطلعت على الكتابين: من هنا نبدأ ومن هنا نعلم، وأعجبت برد الشيخ أسلوباً ومضموناً، وقرَّرت أن أترجم الكتاب لقرَّاء الإنجليزية ليعرف الأمريكان موقف المسلمين الحقيقي من الشيوعية والاشتراكية ونوها، فقعلت ذلك بعد استئذان الشيخ الذي سُرَّ بذلك وسَعدَ به".

وحين استشهد الدكتور الفاروقي غيلة عام 1986م نعاه الشيخ الغزالي إلى الأمة في بعض الصحف التي كان يكتب لها، وذكر أن الشهيد كان صديقاً عزيزاً له، وأنه أول من قدمه إلى قراء الإنجليزية في ترجمة كتابه ذلك، وأشار إلى خسارة الأمة باستشهاده.

كما أن علاقة مودة وإخاء كانت قد ربطت بين الثيخ رممه الله والأخ الدكتور عبد الحميد أبو سليمان قبل سفر الثيخ إلى السعودية، وزادت تلك الصلة وثوقاً بعد ذلك واستمرَّت حتى وفاة الشيخ عليه رمة الله.

أما كاتب هذه السطور فقد بدأت علاقته بالشيخ في وقت مبكر امتد من أيام دراسته فيه الأزهر واستمر حتى وفاة الشيخ رضي الله عنه. 
وحي لاحظ بعض المهتمين ما كان يجري في مصر وفي العالم العربي من اضطراب فكري مع فقدان المرجعية الرشيدة، والفراغ الكبير، كان الثيخ الغزالي في مقدمة الأسماء القليلة التي تحضر إلى الذهن لشغل ذلك الفراغ وملء موقع المرجعية. وكنا نرى أن ذلك يمكن أن يتم بعودة الشيخ إلى مصرن، وتبوئه موقعاً ملائماً يتيح له ملء هذا الفراغ.

كان بعض مبي الشيخ وتلامذته يرون أن لا يعود الشيخ من الجزائر إلى مصر إلا شيخاً للأزهر أو مرشداً عاماً للإخوان المسلمين. فمنصب شيخ الأزهر خاصة بثقله التاريخي، وسمعته الدينية حين يحتله شخص بوزن الشيخ الغزالي ومستوى حضوره ستعود إليه مكانته في الداخل وفي الخارج، وسيتمكن من استقطاب البقية الباقية من العلماء ليعطي للأزهر من جديد آفاقه العالمية، ووظيفته القيادية. وصفات الشيخ ومناقبه الشخصية، وقدراته الخطابية والكتابية وسمعته وصيته، كل ذلك سيكون رصيداً فعالاً في تحقيق هذا الهدف، وفي تحريك كثير من المؤسسات الإسلامية الأخرى التي قد يسهم تحريكها في إعادة مصر لممارسة أثر إسلامي مهم في الداخل وفي الخارج؛ وقد يقضي ذلك على الكثير من أسباب التأزم بين الإسلاميين والنظام داخل مصر.

وحين بدأ بعضهم مساعيهم الحميدة لإقناع القيادة السياسية بهذه الفكرة تضافرت عدة تيارات متذرعة بأسباب عديدة لإحباط هذه المحاولة: منها أن تاريخ الشيخ الحافل بالكفاح على جبهات عديدة أوجد كثيراً من المخاوف من أن الشيخ قد يحرك كل هذه المؤسسات إلى ألفت أن يكون على قمة الهرم فيها رجال لا تتجاوز اهتماماتم الدائرة العلمية المتخصصة بكثير. أما الشيخ الغزالي فمن المتعذر لشخص مثله أن يجصر اهتماماته بهذه الدائرة، فطبيعة الداعية فيه والهموم التي يحملها، وتتبعه لقضايا الإسلام والمسلمين في سائر بقاع الأرض، كل ذلك سيتغلب على طبيعة المنصب، فهو من تلامذة الحركة الإصلاحية الذين لم يكونوا يعرفون الفواصل بين الشأن الدعوي والشأن السياسي والاجتماعي، فكل هموم الأمة همومهم، وكل ثغورها يجب أن تجد من يقف عليها.

ولم ينس له بعض المعارضين لتسلمه المشيخة آنذاك ملاحظاته حول الدستور المصري، فقد كان من أبرز أسباب خلافه مع نظام يوليو في مراحله الأولى تعطيل دستور 1923م؛ فهو لم يقتنع بما اقتنع به بعض 
قادة الإخوان آنذاك، من أن تعطيل الدستور قد تم لأن رجال الثورة يريدون وضع دستور يجسد المبادئ والقيم الإسلامية ويسهم الإخوان أنفسهم في صياغته. حتى بعد أن تم تشكيل لجنة الخمسين عضواً لوضع الدستور الجديد لم تمدأ خخاوف الشيخ، وأشار إلى خطورة أن تبقى البلاد بدون دستور ولو ليوم واحد، ودافع عن كثير من مواد ذلك الدستور المعطل، كما اعترض بعد ذلك على ما أُدخل على الدستور من تعديلات في عهد رئيس مصر الراحل أنور السادات. ولم يتردد الشيخ في إبداء اعتراضه المعلن وموقفه المعارض لزيارة الرئيس السادات إلى القدس، ولم يخف نقده لقانون الأحوال الشخصية الذي صدر في عهده.

كذلك اعتبرت أجهزة الأمن الشيخ محرِضاً على مظاهرة إسلامية انطلقت من الأزهر وبقيادة بعض شيوخه رداً على مظاهرة علمانية مؤيدة لقانون الأحوال الشخصية في الأزهر آنذاك، ولم ينس له بعضهم نقده اللاذع للممارسات والأخطاء الحكومية التي أدت إلى هزيمة عام 1967م، مما دفع الرئيس الراحل أنور السادات إلى إصدار أمر باعثقاله أثناء وجوده خارج مصر في الجزائر للمشاركة في ملتقى إسلامي فيها. المهم أن هذه الأمور - كلها- مع طبيعة المرحلة ومتغيراتا المختلفة حالت دون قبول فكرة تعيين الشيخ الفزالي -رحمه الله- شيخاً للأزهر الشريف.

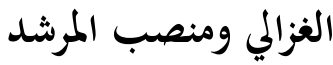

أما الاقتراح الثاني فقد حالت دون قبوله - كذلك- بعض الأسباب؛ فالاقتراح كان يستند أساساً إلى كون الشيخ واحداً من أعضاء الهيئة التأسيسية للإخوان المسلمين الأحياء في ذلك العهد، وإلى أن مكانته العلمية، وشخصيته وسمعته سيكون عائدها خيراً على كيان الجماعة وسمعتها، وأن تسلمه لقيادة الجماعة قد يسمح بإيجاد علاقات طبيعية مفتوحة مع نظام الحكم في مصر ومع النظم الأخرى خارجها. وقد يسمح كذلك بانفتاح الجماعة على التيارات السياسية المختلفة، وينقي سمعة الجماعة من سائر ما علق بها أثناء اختلافها وصراعاها مع نظام الرئيس جمال عبد الناصر. وكان هناك اعتقاد بأن صفات الشيخ وطبيعته المنفتحة ستسهّل إعادة توحيد الصفوف الإسلامية في مصر وبناء الجبهة الداخلية، وتنهي مرحلة الفصام بين رجال الفكر والدعوة، ورجال الفقه والحركة. 
أما الاعتراض على هذه الفكرة فقد كان يستند إلى أن الشيخ الغزالي وأن كان مِنْ أعضاء "الهيئة التأسيسية للجماعة"، إلا أنه ليس الأسنّ بينهم؛ فالأستاذ محمد حامد أبو النصر -رحمه الله- كان أسن منه. كما أن فترة سجنه لم تطل كما طال سجن غيره بسبب تخليه عن معارضة الرئيس عبد الناصر. وقد اعتبر اختلافه مع المرشد حسن الهضيبي -رممه الله- وفصله من الجماعة عام 1953م بعد سبعة عشر عاماً من العمل داخلها، دليلا على عدم الانضباط، وعدم الالتزام بالقواعد التنظيمية.

ومع أن ذلك -كله- قد نوقش، وبيَّن الذين تبنّوا فكرة ترشيح الشيخ الغزالي لمنصب "المرشد" ضعف ما ذكر من اعتراضات، وتمافته أمام الفوائد الكبيرة التي يمكن أن تجنيها الجماعة، بل والعمل الإسلامي بصفة عامة من اختياره مرشداً للجماعة، إلا أن المحاولة أخفقت، وانتهت بالرفض التام. ولم يشفع للشيخ تتلمذه المخلص على الأستاذ الشهيد حسن البنا، وانفعاله الكامل بشخصيته، حتى إنه ليكاد يتمثل شخصيته فضلاً عن هضمه لفكره، واستيعابه لعلومه وآدابه. وهؤلاء كان من بينهم مَنْ إذا جلسوا مجالس المراجعة لتاريخ الأمة كثيراً ما يتمنون لو أن أمير المؤمنين علياً جاء بعد أمير المؤمنين عمر دون فواصل، ويؤكدون أنه

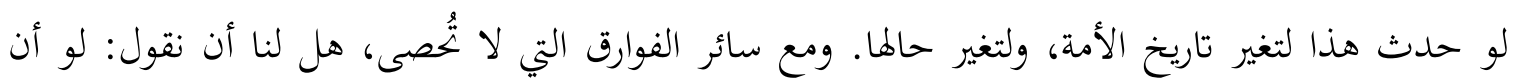
رجلاً بوزن الثيخ الغزالي -رحمه الله- تسلم زمام إرشاد هذه الجماعة خلال السبعينات وما تلاها لكان الحال غير الحال ولكن قدَّر الله وما شاء فعل.

\section{تنلمذه على دروس الثهيد حسن البنا}

قد لا يدري الكثيرون أن خطب الشيخ الغزالي ودروسه في الأزهر وفي جامع عمرو بن العاص وغيرها من المساجد في القاهرة وغيرها من مدن مصر، ومحاضراته في الجيش المصري قبل 1973م وفي طلاب الجامعات المصرية، وكذلك دروسه في جامعة أم القرى وفي الجزائر، ما كانت إلا تلخيصاً دقيقاً لدروس الشهيد حسن البنا خاصة، ودروس قادة التيارات الإصلاحية من أواخر القرن الماضي وأوائل هذه القرن، مع ما يضيفه الشيخ من فيض علومه وصائب فكره، ولذلك كان -رحمه الله- ينفعل بما يقول أكثر مما ينفعل به 


\section{الشيخ والمعهد العالمي للفكر الإسلامي}

وكان يمكن للشيخ - بعد إخفاق المسعيين الآنفي الذكر - أن يعيش خارج مصر أستاذاً في جامعة من الجامعات، يبث أفكاره وبتحاربه وخبراته بين طلابه ومريديه فيمتلئ وقته، ويشعر بالسعادة التي يحتاجها ليستمرَّ في حالة الإنتاج والعطاء. إلا أن القائمين على أمر المعهد رأوا أنه لا بد من البحث عن بديل للشيخ، والعمل على استقراره في مصر، بحيث تُهيأ له في حدود الإمكانات المتواضعة للمعهد سبيل البقاء فيها. فالجميع كانوا يعرفون مزايا الشيخ ويقدروها، ويدركون أن فاعلية هذه المزايا ستضضاعف أضعافاً كثيرة بوجوده في مصر، فهناك ارتباط وثيق بين شخصية الشيخ الغزالي وشخصية مصر، وعبقرية الرجل وعبقرية المكان -كما يقول عالم الجغرافيا المصري جمال حمدان- وكلفني مجلس أمناء المعهد بالعمل على تحقيق ذلك فسافرت إلى الثيخ وفاتحته بالأمر، شرحت له أبعاده كلها.

فهشّ رحمه الله لذلك وبشّ، وقدّر العرض كثيراً ودعا للمعهد وللقائمين عليه، ورأى المعهد وفكره امتداداً حقيقياً لمسيرة الحركة الإصلاحية. وتم التفاهم على جدول زمني يعود الثيخ فيه إلى مصر، ليكون رئيس المجلس العلمي لمكتب المعهد فيها، وواحداً من أبرز مستشاريه وموجهي مسيرته. وقد كان "المجلس العلمي" لمكتب المعهد في القاهرة يضم نخبة من المفكرين، لا على مستوى مصر وحدها، بل على مستوى أعمّ وأشمل. فقد كان هذا المجلس يضم الأستاذ الدكتور أحمد كمال أبو الجمد، والأستاذ المستشار طارق البشري، والأستاذ الدكتور محمد عمارة، والأستاذ الدكتور محمد عثمان نجاتي، والأستاذ الدكتور محمد سليم العوا، والأستاذ الدكتور جمال الدين عطية، ثم انضم إليه الأستاذ الدكتور سيد دسوقي حسن والأستاذ الدكتور علي جمعة عبد الوهاب والأستاذ الدكتور عبد الوهاب المسيري، والأستاذة الدكتورة زهيرة عابدين، يضاف إلى هؤلاء بجموعة من الأساتذة الخبراء الذين للمجلس أن يدعوهم للاستماع إلى آرائهم إذا ما عرضت أمور تحتاج إلى خبرات أو تخصصات إضافية.

وكان هذا المجلس يجتمع شهرياً -أو كلما دعت الحاجة- في مكتب الشيخ الغزالي الذي يقع تحت منزله، وقد كانت تلك مرحلة إنتاج خصب على مستوى الندوات والمحاضرات والبحوث، وكان الشيخ واسطة العقد في كل تلك النشاطات قَلَّ أن يتخلف عن ندوة أو محاضرة أو لقاء. 
وفي هذه المرحلة أعد الشيخ دراساته القيمة في كيفية التعامل مع القرآن، وكيفية التعامل مع التراث الإسلامي، وقضايا الفنون وموقف الإسلام منها، وكثير من القضايا الأخرى.

وصدر له عدد من الكتب المهمة هي: كيف نتعامل مع القرآن والسنة النبوية بين أهل الفقه وأهل الحديث، والتفسير الموضوعي، وتراثنا الفكري في ميزان الشرع والعقل، وما يقرب من ألف محاضرة ومقالة كبيرة وصغيرة. وقد كان أهم ما تميز فكر الشيخ الغزالي به في هذه المرحلة أن صار فكراً كثيراً ما يتعرض للحوار والمناقشة الجماعية من خلال لقاءات المعهد وندواته وبجالسه، قبل أن يصوغه الشيخ ويضعه في قالبه الأخير.

وهذه ميزة لم تتوافر لفكر الثيخ في كتبه الأخرى إلا في فقه السيرة، وما ورد فيه من الأحاديث، ودراسات محدودة أخرى جرى إعدادها أثناء التعليم والتدريس، سواء في السعودية أو في الجزائر أو في زياراته لَعَرَ .

وفي تلك المرحلة المباركة من عمر الشيخ، أتيح له تسجيل أهم خبراته خلال حياته الحافلة بالعطاء. فقد قرّر المعهد تنفيذ مشروع لتسجيل خبرات جملة من أعلام العصر وخلاصة بتحاربم في الحياة بالصوت والصورة، على أن يتم استخلاص تلك الخبرات والتجارب بحوارات علميّة مكثفة يقوم بها أساتذة محاورون أكفاء بعد دراسة مستفيضة في تراث من يجري الحوار معه وإنتاجه العلمي. وتقرر البدء بكل من الشيخ الغزالي والدكتور زكي نجيب محمود. وجمُعت كتب الشيخ وقدمت لمجموعة من أفضل المفكرين لدراستها أولاً، ليقوموا بمحاورة الثيخ في أفكاره، ويتتبعوا مسيرة حياته العلمية والفكرية ويبرزوا جوانب من مقوّمات شخصيته ومكوناها. وكان من بين من حاوروا الشيخ الأستاذ المستشار طارق البشري، والأستاذ الدكتور محمد سليم العوا، والأستاذ الدكتور محمد كمال إمام، والأستاذ الدكتور جمال الدين عطية، والأستاذ الدكتور محمد عمارة، والأستاذة صافيناز كاظم. وقد أربت هذه التسجيلات المصورة على خمس عشرة ساعة تولت بالتحليل والحوار أهم جوانب حياة الشيخ الحافلة؛ ولعل من أهم ما ورد فيها أها عالجت "ما وراء" فكر الشيخ الذي دُوِّن في كتبه ودروسه ومقالاته. كما أفها تعرضت لتقديم تفسيرات مباشرة وصريحة لكثير من الأحداث والمواقف التي لمم يعرف المتصلون بحياة الشيخ أو معظمهم تفسيراً صريحاً لها. 
وقد اشتملت تلك التسجيلات على نوع من ممارسة النقد الذاتي، المراجعات التي لم تعد معطيات عصرنا تسمح بها أو تتسع لمثلها حيث ساد التعالم الكاذب، والإصرار على المواقف حقها وباطلها؛ لكن الشيخ -رمه الله- رجل أوّاب، سرعان ما يرجع إلى الحق أو الصواب أو الرأي الراجح إذا عرفه. فهو يروي قصة رجوعه عن نقد بعض الصحابة -رضوان الله عليهم- الذين اشتهروا بمعارضة الإمام علي كرم الله وجهه ورضي عنه، فيقول: "دعاني الباقوري يوماً لمنزله، وكنت صديقاً له، فما أن جلستُ حتى قال: "ما الذي بينك وبين عمرو بن العاص يا شيخ محمد؟ فقلت: ليس بيني وبينه شيء اللهم إلا أنني أخطب في جامع عمرو الجمعة. قال الباقوري: دعلك من هذا واستمع لرؤياي هذه، ولك -بعد ذلك- تأويلها. ثم قال الباقوري: "رأيت فيما يرى النائم وأنا في منزلي هذا أن منادياً ينادي: الوالي قادم، الوالي قادم! فتساءلت: ومن هو الوالي فأجابوا: عمرو بن العاص. فدخل فنظرت إليه فهبته، ثم قال عمرو: قل للشيخ الغزالي: إني قد عفوت عن انتقاصه ونقده لي لأنه قد عمّر مسجدي". يقول الشيخ الغزالي: فأجهشت بالبكاء، وأدركت أن في الرؤيا إشارة إلى شيء كان في نفسي، وكنت أصرح ببعضه أحياناً، وهو كراهتي لمحاربي علي ومخالفيه من الصحابة، وبخاصة معاوية وعمرو. وبعد أن فرغت، قلت للباقوري: إنني أعلن أمامك توبتي ورجوعي عن ذلك: فكل من صحبوا رسول الله -صلى الله عليه وسلم- يجب أن يُتركوا لله ولرسوله، فذلك هو الأولى والأليق بنا، ولا ينبغي أن نضع مسؤولية خيبتنا وتراجعنا عليهم". وما يدريني ما أكون لولا عمرو لعلني لو لم يدخل عمرو مصر ويفتحها بالإسلام وله، أكنت الآن من المسلمين؟".

\section{تعميره مسجد عمرو بن العاص}

كان مسجد عمرو بن العاص-فاتح مصر- في مدينة الفسطاط جنوبي القاهرة، في منطقة شعبية عرفت "بمصر القديمة"، أحيط بالمباني العشوائية المتواضعة ومصانع الآجر ومدابغ الجلود فأصابه إهمال شديد، وبقي بجرد أثر من الآثار الإسلامية في مصر. لكن مسؤولية إدارة مسجد عمرو بن العاص بقيت منوطة بوزارة الأوقاف، فهيئة الآثار ترى الأوقاف مسؤولة عنه وعن ترميمه والمحافظة عليه، وتتوقع منها أن تتولى ذلك، حتى كاد أول جامع في مصر أن يضيع ويندثر. ولما تولى الدكتور عبد الحليم محمود -رحمه الله- وزارة الأوقاف كان الشيخ الغزالي معه مديراً عاماً للمساجد. فاستدعى الدكتورً عبدُ الحليم الشيخ الغزالي 
وطلب منه أن يتولى خطابة الجمعة في جامع عمرو، وفي هذا يقول الشيخ الغزالي: "فقلت للشيخ عبد الحليم، وكان رجلاً صالحاً: لقد كنت أخطب في الأزهر، ثم منعت من الخطابة فيه، ولا مانع لدي من أن أعود للخطابة فيه". قال: "فأطرق الشيخ عبد الحليم قليلاً، ثم قال: أريدك أن تخطب في جامع عمرو بدءً من الجمعة القادمة". يقول الغزالي: "كما في يوم الثلاثاء، فقلت له: أعطني فرصة حتى أهيئ الجامع، يقول الشيخ الغزالي: "فذهبت إلى المسجد فوجدت الأتربة المتراكمة والقمامة قد بلغت في بعض جوانبه ما بين الأرض والسقف، فدعوت طلابي الذين كنت أدرس لهم في الأزهر -وكانوا حوالي خمسين- وأخبرقم بما جرى، وطلبت منهم مساعدني على إعداد جامع عمرو لصلاة الجمعة، فتم ذلك في وقت قصير. وبعد أن سمع طلابي في جامعة القاهرة وغيرها احتجوا أنني لم أشركمم مع طلاب الأزهر في هذا الخير.

وبعد أن صليت الجمعة الأولى أدركت أن الله -تعالى- قد ألم الرجل الصالح الشيخ عبد الحليم محمود ليعمر هذا المسجد المبارك ويجييه، ليكون شاهداً على عراقة انتماء هذا البلد وشعبه إلى الإسلام،

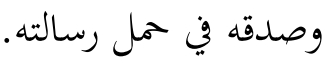

وقررت أن أجعل من خطبتي فيه سلسلة متصلة من التفسير الموضوعي لآيات الكتاب الكريم، وأن أبدأ من أول القرآن وأستمر حتى غايته إن شاء الله ومدّ في الأجل. ولم تمض جمعتان أو ثلاث حتى صار الجامع الكبير يضيق بالمصلين على اتساعه، وكان كثير من المصلين على اتساعه، وكان كثير من المصلين يأتون من خارج القاهرة في سيارات نقل يستأجروها". ويقول الثيخ: "ولقد واصلت ذلك حتى بلغت سورة النساء. وفي تلك الفترة كان قانون "الأحوال الشخصية" يُعرض على البرلمان، فظن أنور السادات أنني تعمدت تفسير آيات من هذه السورة في هذه الفترة لبيان مخالفات هذا القانون لأحكام القرآن، فمنعني من الخطابة في وقت كان عدد المصلين قد قارب خمسة عشر ألفاً أو يزيدون".

وهنا قرَّر الشيخ الهجرة إلى مكة المكرمة، حيث عمل أستاذاً في أم القرى، ومتحدثاً في الإذاعة، وكاتباً في كثير من المجلات والجرائد السعودية حتى بلغت أحاديثه المذاعة ألف حديث، معظمها مسلسلات في إذاعة القرآن الكريم. 


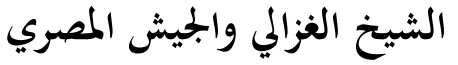

الشيخ الغزالي شاهد على مراحل حرجة من حياة مصر وجيشها وشعبها (سنة 1948، 1956،

1973م)، ويرى في منتسبيه -جنوداً وضباطاً وضباط صف -عناصر مخلصة مستعدة للتضحية والبذل والفداء، وله رأي في قيادات الحروب الثلاث الأولى. ويرى في هزيمة 1967م هزيمة كبرى وعاراً ألحقته "القيادة الغافلة المخدرة" -حسب تعبيره- بجيش وشعبٍ لا يستحقان ذلك منها، وقد منحاها كل الولاء والتأييد. ويرى في استبداد القيادة وإهمالها لأبسط قواعد الشورى أو الديمقراطية أسباباً مباشرة في الهزيمة، وقد كتب في ذلك وتحدث باستفاضة. وفي معرض الحديث عن حرب العاشر من رمضان سنة ثلاث وسبعين، يرى أن من أهم أسباب النصر في الانطلاقة الأولى للحرب تلك الروح المعنوية الإسلامية العالية التي استطاع أن يبثها في أبناء القوات المسلحة خمسون مرشداً من أفضل وأعظم الدعاة والخطباء الأزهريين، كان على رأسهم الشيخ عبد الحليم محمود والشيخ الغزالي نفسه. فهؤلاء المرشدون هم الذين استطاعوا تعبئة أبناء القوات المسلحة تعبئة نفسية عالية جعلت من كثير منهم نماذج يمكن أن توضع بجانب تلك النماذج الحية التي تتابعت قوافلها منذ عصر النبوة حتى يومنا هذا. لقد كان يقول لأبناء الجيش المصري مثلاً: "... الإيمان مواقف، وهناك أناس متخصصون في الهروب من المواقف إلى مواقف أخرى، هي الباطل بعينه وإن لبست أحياناً ثوب التدين؛ فالفرار من الجهاد لا يغني عنه المكث في صحن المسجد". ويقول: "إن أزمة الشهامة دليل على فتور روح التدين والرجولة وانطلاق السعار الحيواني دون قلق، والأمر يمتاج إلى معالجة سريعة؛ فإن استقرارا المنكر على هذا النحو إيذان بالانحدار والضياع وتتابع الهزائم المذلة".

لقد استطاع الشيخ الغزالي ورفاقه أن يعيدوا بناء نفسية المقاتل المصري بناءً إسلامياً، وأن ييثوا في شرايينه الدماء التي كانت تحتاجها معركة الأمة مع أعدائها ومنتهكي حرماتا، وغاصبي أرضها، ومهددي

رحم الله الشيخ الغزالي وتقبله في الصالحين، فالحديث عنه طليّ، والذكريات معه تترى.

لقد فقدت فيه الأمة علماً من أعلامها النجباء، وفقد فيه المعهد الموجه الفاعل، والرائد الأمين. 
ووفاءً لذكراه وعرفاناً لفضله، فقد رأت إدارة بجلة إسلامية المعرفة وهيئة تحريرها إصدار عدد خاص عنه للحديث عن شخصيته وعلمه وجهاده في سبيل إصلاح شأن الأمة وبتحيد ثقافتها واستنهاض طاقاتما كي تستأنف مسيرتحا الرسالية قائمة بالعدل شاهدة على الناس بالحق. وقد أسهم في مادة هذا العدد كوكبة من أبناء الأمة ذوي تخصصات علمية واهتمامات فكرية متنوعة، فكانت إسهاماقم جميعاً إبرازاً لجوانب وأبعاد في شخصية الشيخ وفكره تنم كلها عن ثراء مسيرته وتنوع عطائه وغزارة تراثه العلمي، ونخن لا ندعي أن مادة العدد قد استنفت دراسة كل الجوانب والأبعاد في شخصية الشيخ وفكره، فما نقدمه هنا ليس إلا فتحاً للباب ولفتاً للانتباه حتى يقوم المهتمون بمسيرة الفكر الإسلامي والدارسون لقضاياه بدراسات أكثر شمولاً تنظر إلى إسهامات الثيخ الغزالي في علاقتها وتفاعلها مع غيرها من الإسهامات وفي سياق حركة التجديد الفكري والإصلاح الثقافي والاجتماعي التي انطلقت منذ منتصف القرن الماضي. وقد حظينا في هذا العدد بنشر مقالة دبجتها يراع الشيخ في الأيام الأخيرة من حياته هي مقالة الإسلام والثقافة العبية في حياتنا المعاصرة، كما حظينا بنشر مقتطفات من مذكراته التي هي الآن قيد الإعداد للنشر في كتاب.

ألا جزى الله الثيخ الغزالي عن الإسلام وأمته بخير ما يجزي به عباده الصالحين، والحمد لله رب العالمين.

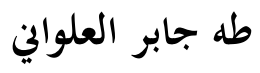

